\title{
Geç Dönemde Gebeliğin Sonlandırılmasının Bir Nedeni Olarak Dev Antenatal Hidronefroz: Fetal Otopsi Olgusu
}

\author{
A Giant Antenatal Hydronephrosis as a Reason of Late Pregnancy Termination: A Fetal \\ Autopsy Case
}

Adalat Hasanov, Jamal Musayev, Ilaha Karimova, Hikmat Zeynalov

Azerbaycan Tip Üniversitesi, Patoloji Anabilim Dalı, Azerbaycan

\section{Özet}

Geç dönemde gebeliğin sonlandırılması tüm dünyada önemli tıbbi ve etik sorunlar oluşturmaktadır. Bu dönemde gebeliğin sonlandırılması için ciddi tıbbi ve ya sosyal endikasyonların bulunması gerekmektedir. Burada antenatal hidronefroza bağlı annenin isteği ile gebeliğin geç dönemde sonlandırılmasına dair bir olgu sunulmuştur. Antenatal hidronefroz, postnatal dönemde spontan gerileme göstermesi ve tedavi olanaklarının bulunması nedeni ile gebeliğin sonlandırılması için ciddi bir endikasyon oluşturmamaktadır. Özellikle kürtaj komplikasyonlarının sık rastlandığı geç dönem gebeliklerde bu gibi nedenlere dayanarak gebeliğin sonlandırılması risklidir. $\mathrm{Bu}$ bakımdan sağlık çalışanlarının anne adayına ve ailesine mevcut hastalık, hastalığın seyri ve tedavisi konusunda yeterli bilgi vermesi önem arz etmektedir.

Anahtar kelimeler: Antenatal hidronefroz, Fetüs, Otopsi, Ultrasonografi.

\section{Giriş}

Geç dönemde (gebeliğin 20. haftası ve üzeri) gebeliğin sonlandırılması tüm dünyada önemli tıbbi ve etik sorun oluşturmaktadır. Bu dönemde gebeliğin sonlandırılması için ciddi tıbbi ve ya sosyal endikasyonların bulunması gerekmektedir. Fetüste saptanan gelişim bozuklukları bu nedenlerin bir kısmını oluşturmaktadır. Son 25 yılda ultrasonografinin (USG) yaygin kullanımı ile birlikte antenatal dönemde saptanan fetal anomalilerin oranında da artış görülmüştür (1). Hayatı tehdit etmeyen ve postnatal dönemde tedavisi mümkün olan antenatal hidronefroz gibi nedenlerden dolayı gebeliğin sonlandırılmasına az rastlanmaktadır. Bu makalede; fetuiste antenatal hidronefroz saptanan geç dönem bir gebeliğin, annenin isteği ile sonlandırıldı̆̆ sunulmuştur. Buna neden olan tıbbi-psikolojik faktörler ve fetüsün otopsi bulguları gözden geçirilmiştir.

Sorumlu Yazar: Jamal Musayev

Azerbaycan Tip Üniversitesi,

Patoloji Anabilim Dall, Azerbaycan

E-mail: patolog.jamalmusaev@gmail.com

\section{Abstract}

The late termination of pregnancy constitutes the important medical and ethic problems around the world. There should be serious medical and social indications for termination of pregnancy in this period. Here, a case of late termination of pregnancy with the request of the parents due to antenatal hydronephrosis was presented. Antenatal hydronephrosis does not constitute a serious indication for late pregnancy termination because of its spontaneous regression and the availability of treatment options postnatally. The termination of pregnancy due to such reasons is risky, especially in late period of pregnancy, which abortion complications are frequent. In this regard, giving sufficient information about presented disease, its course and treatment to future mother and her family by healthcare workers is important.

Keywords: Antenatal hydronephrosis, Fetus, Autopsy, Ultrasonography.

\section{Olgu Sunumu}

İlk gebeliğini geçiren 22 yaşındaki olgumuzda gebeliğin 23 . haftasinda yapılan rutin ultrasonografide (USG) fetüste abdominal kavitenin sol yarısını dolduran 24x37 mm boyutlarında kistik lezyon saptanmıştır (Şekil 1). Saptanmış olan lezyonun hidronefrozu düşündürdüğü, fakat neoplastik bir süreçin de ekarte edilemediği belirtilmiştir. Daha önce yapılan rutin USG incelemelerinde fetüste herhangi bir anormallik bulunmadığ 1 bildirilmiştir. Annenin genel durumunda ve klinik tetkiklerde olağandışı bulgulara rastlanmamıştır. Ailenin yakın akrabalarının (annenin ve babanın kardeşleri) çocuklarında küçük yaşta mortalite ile sonuçlanan çeşitli neoplastik hastalıkların bulunması nedeni ile olgumuzun ailesi tarafından bu olasılık gözönünde bulundurulmuş ve gebeliğin sonlandırılmasına karar verilmiştir. Bakü'de, özel bir merkezde gebeliğin 24. haftasında uygulanan sonlandırma işleminin ardından fetuis ve plasenta patolojik inceleme için gönderilmiştir. Patolojik incelemede 33 cm uzunlukta ve 925 gr ağırlıkta erkek fetüste, sol böbrek hizasında yerleşmiş ve abdominal kaviteyi dolduran, içi sıvı ile dolu kistik kitle bulunmuştur (Şekil 2). Bu bulgu dışında fetüste her hangi bir özellik görülmemiştir. Mikroskopik 
incelemede kist duvarının atrofik böbrek parankiminden oluştuğu belirlenmiştir. Fetüs üzerinde yapılan inceleme sonucu, sol böbrekte üreteropelvik darlığa bağlı antenatal hidronefroz bildirilmiştir.

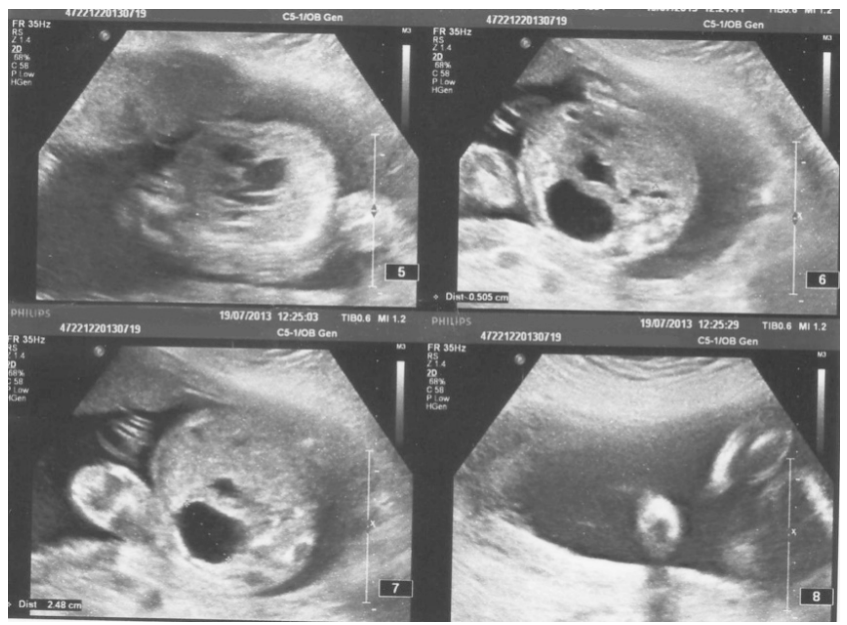

Şekil 1. USG'de fetüste abdominal kavitenin sol yarısını dolduran kistik lezyon.

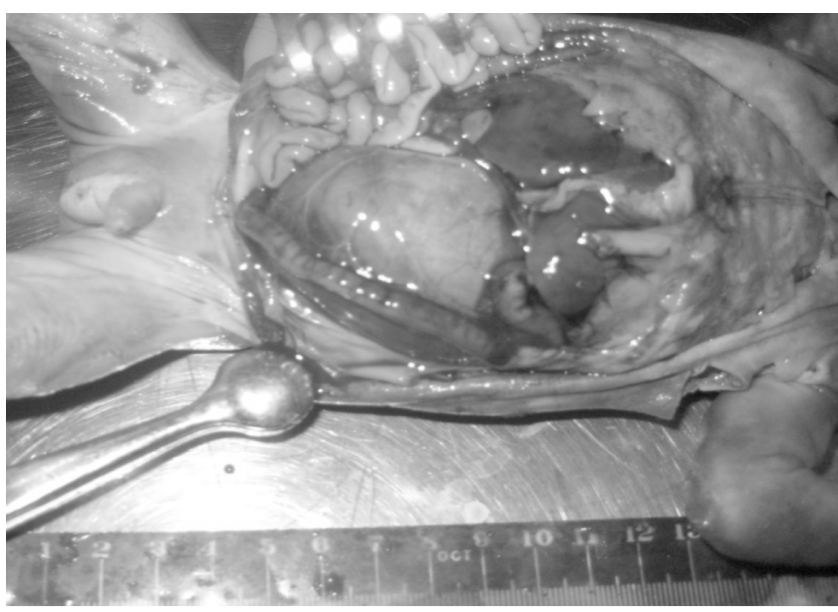

Şekil 2. Abdominal kavitede sol böbrek hizasında kistik kitle.

\section{Tartışma}

Antenatal dönemde tespit edilen üriner sistem anomalilerinin insidansı 1000 canlı doğumda 2-9'dur. Hidronefroz antenatal dönemde saptanan tüm üriner sistem anomalilerinin \%59-87'ni oluşturmaktadır (1,2). Fizyolojik ve patolojik olarak iki tipi ayırt edilmektedir. Patolojik antenatal hidronefrozun en sik görülen nedeni üreteropelvik birleşke darlığıdır. İlk gebeliklerde daha sık görüldüğü bildirilmiştir (2). Genellikle gebeliğin ikinci ve üçüncü trimesterinde USG ile kolaylıkla saptanabilmektedir. USG bulgularına dayanarak Fetal Üroloji Derneği (FÜD) antenatal hidronefrozun dört farklı evresini ayırt etmiştir (Tablo 1) (3). Bununla birlikte, antenatal dönemde fizyolojik ve patolojik antenatal hidronefroz ayırımı da USG ile yapılabilmektedir (4). Antenatal dönemde hidronefrozu taklit eden bazı kistik abdominal lezyonlar gibi, hidronefroz da USG'de aynı lezyonlara benzerlik gösterebilir (5). Özellikle renal parankimde önemli ölçüde incelme ve ya total atrofi oluşan FÜD'e göre evre IV olgularda renal parankimin ayırt edilememesi benzer sorunların yaşanmasına neden olabilir. Olgumuza ait USG bulguları geriye dönük incelendiğinde tespit edilen kistik abdominal kitlenin FÜD'e göre evre IV antenatal hidronefroz ile uyumlu olduğu görülmüştür.

Tablo 1. Fetal Üroloji Derneği’nin hidronefroz evrelemesi

\begin{tabular}{|l|l|}
\hline Evre 0 & $\begin{array}{l}\text { Hidronefroz yok, santral renal kompleks } \\
\text { intakttır. }\end{array}$ \\
\hline Evre I & $\begin{array}{l}\text { Ultrasonografide yalnız renal pelvis görülmekte; } \\
\text { dilate pelvis görüntüsü }\end{array}$ \\
\hline Evre II & $\begin{array}{l}\text { Renal pelviste orta derece dilatasyon; bir kaç } \\
\text { kaliks görülmekte }\end{array}$ \\
\hline Evre III & $\begin{array}{l}\text { Neredeyse tüm kaliksler görülmekte; geniş renal } \\
\text { pelvis ve iyi korunmuş parankim bulguları }\end{array}$ \\
\hline Evre IV & $\begin{array}{l}\text { Neredeyse tüm kaliksler görülmekte; } \\
\text { parankimde incelme ve atrofi bulguları }\end{array}$ \\
\hline
\end{tabular}

Antenatal hidronefroz neonatal dönemde genellikle klinik bulgu göstermemektedir. Shimada ve ark. tarafından yapılan 562 olgunun ele alındığı bir çalışmada olguların sadece \%1,6`da renal disfonksiyon, ellenen abdominal kitle ve üriner sistem enfeksiyonlarına bağlı bulgular gözlemlenmiştir (6). Literatürde dev abdominal kitle ile prezente olan hidronefroz olguları da görülmüştür (7). Olgularda çoğunlukla kontralateral böbrek sağlıklı olduğu için nefrolojik semptomlar karakteristik özellik değildir. Bununla birlikte bazı çalışmalarda antenatal hidronefrozlu olgularda kontralateral böbrekte multikistik hastalık olasılığının yüksek olduğundan bahsedilmektedir (8). Alconcher ve ark. tarafindan yapılan bir çalışmada ise bilateral antenatal hidronefroz oranının yaklaşık \%40 olduğu bildirilmektedir (9).

Postnatal dönemde çeşitli tedavi seçenekleri mevcuttur. FÜD'e göre evre I konjenital hidronefroz olgularının tamamında, evre II olguların ise büyuik kısmında postnatal dönemde medikamentoz destek ile spontan gerileme görülmektedir ve bu olgulara takip uygulanmaktadır. Buna karşın FÜD’e göre evre III olgularının büyük kısmında ve evre IV olguların tamamında postnatal dönemde cerrahi müdahaleye ihtiyaç duyulmaktadır (10-12). Görüldüğü üzere antenatal hidronefrozun farklı tedavi seçenekleri bulunmaktadır, Bu nedenle özellikle geç dönemde gebeliğin sonlandırılması için endikasyon oluşturmamaktadır. Bu bakımdan özellikle geç dönemde alınan kürtaj kararlarında 
endikasyon oluşturan bu tür lezyonların dikkatlice gözden geçirilmesi ve neoplastik lezyonlardan ayırt edilmesi önemlidir.

Farklı ükelerde gebeliğin sonlandırılmasına dair farklı uygulamalar bulunmaktadır. Örneğin Türkiye’de yasal olarak 10. gebelik haftası doluncaya kadar ve her iki eşin isteği üzerine normal bir gebelik sonlandırılabilir. Gebelik süresinin 10. haftanın üzerinde olduğu durumlarda yalnız belli endikasyonlara dayanarak ilgili daldan uzman doktorların kararıyla gebelik sonlandırılabilir (13). Ayrıca Türk Ceza Kanunu'nun 99/6. maddesi uyarınca tecavüz mağdurlarında bu süre 20 haftadan fazla olmamak kaydı ile herhangi bir endikasyon olmaksızın gebelik sonlandırılabilir. Aynı şekilde Rusya'da, Azerbaycan'da ve bir çok ülkede gebeliğin 12. haftasından sonra yapılan kürtajlar kısıtlanmaktadır. Bu rakam İtalya'da 13; Almanya, Macaristan, Avusturya'da 14; İsveç'te 18; Singapurve Britanya'da ise 24. haftadır (14).

Sonlandırma kararının verilmesi özellikle de yenidoğan için yaşayabilme sınırının aşıldığı gebeliğin 20. haftası ve sonrası döneminde (geç dönemde) hem doktor, hem de aile için zor bir karardır. ABD’de bu oran tüm kürtajların \%0,08'ini oluşturmaktadır (15). Genel yaklaşım, yaşama kabiliyetini kazanmamış fetüslerde, sağlıklı yaşam ile bağdaşmayan bir malformasyon saptanması durumunda gebeliğin sonlandırılması seçeneğinin aileye sunulmasıdır. Gebelik takibinde USG'nin yaygın kullanımıyla bu tür fetüs hastalıklarının erken dönemde tesbit edilmesi doğal olarak geç dönem gebelik tahliyesi oranını da düşürmektedir. Buna karşın 2. trimesterde takibi yeterli şekilde yapılmayan gebeliklerde geç gebelik terminasyonu oranı doğal olarak daha yüksek bulunmaktadır. Bir çalışmada gebeliğin sonlandırılmasında en sık gecikmeğe neden olan etkenin $\% 65,6$ gibi bir oranla USG taramasındaki yetersizlikler olduğu belirtilmiştir (16).

Antenatal hidronefroz, tüm gebeliklerin \%1,0-4,5'de görülmektedir (11). Bu nedene bağlı olarak geç dönemde gebeliğin sonlandırılması nadiren yapılmaktadır. Türkiye’de yapılan geniş çaplı çalışmalarda gebeliğin 23. haftası ve sonrasında yapılan kürtajların sadece yaklaşık 0,4\%'ü antenatal hidronefroz nedeni ile uygulanmıştır (17). Bir çok ülkede olduğu gibi Türkiye'de de tek taraflı hidronefroz nedeni ile gebeliğin sonlandırılması, konu ile ilgili branşların görüşü doğrultusunda, tıbbi hata olarak kabul edilebilir. Fakat olgumuz gibi neoplastik lezyonların tam olarak ekarte edilemediği, FÜD’e göre evre IV olgular kürtaj kararının alınmasına neden olabilir.

Birçok ülkede gebeliğin sonlandırılması kararı bu amaçla oluşturulmuş etik kurullar tarafından verilmektedir. Bu tür etik kurullar annenin ve fetüsün sağlık durumu, ailenin sosyal sorunları ve fetüs hakları gibi birçok etkeni değerlendirerek sonlandırma işlemi ile ilgili en doğru kararı vermekle yükümlüdür. Türkiye'de yapılan bir çalışmada etik kurul kararı ile tahliye edilen olguların yaklaşık \%30'unda gebelik süresinin 24 haftadan fazla olduğu bildirilmiştir (18).

\section{Sonuç}

Antenatal hidronefroz gebeliğin takibinde USG ile kolaylıkla saptanabilen ve sik rastlanan bir hastalıktır. Postnatal dönemde hastalığın bazı olgularda spontan gerileme göstermesi, çeşitli tedavi olanaklarının bulunması nedeni ile gebeliğin sonlandırılması için endikasyon oluşturmamaktadır. $\mathrm{Bu}$ bakımdan antenatal dönemde, özellikle evre IV hidronefrozun neoplastik lezyonlardan dikkatlice ayırt edilmesi gereklidir. Sağlık çalışanlarının anne adayına ve ailesine bu tür lezyonlarla prezente olan hastalıklar, bu hastalıkların seyri ve tedavisi konusunda yeterli bilgi vermesi her toplumda önem arz etmektedir.

\section{Kaynaklar}

1. Shokeir AA, Nijman RJ. Antenatal hydronephrosis: Changing concepts in diagnosis and subsequent management. BJU Int 2000;85:987-94.

2. Kumar M, Thakur S, Puri A, Shukla S, Sharma S, Perumal V, et al. Fetal renal anomaly: factors that predict survival. J Pediatr Urol 2014;10:1001-7.

3. Fernbach SK, Maizels M, Conway JJ. Ultrasound grading of hydronephrosis: introduction to the system used by the Society for Fetal Urology. Pediatr Radiol 1993;23:478-80.

4. Zhan X, Tao G, Cheng L, Liu F, Li H, Liu S. Ultrasound score: a new method to differentiate fetal physiological and pathological hydronephrosis. Eur J Obstet Gynecol Reprod Biol 2010;151:26-32.

5. Yapanoğlu T, Alper F, Özbey İ, Aksoy Y, Demirel A. Giant hydronephrosis mimicking an intraabdominal mass. Turk J Med Sci 2007;37:177-9.

6. Shimada K, Matsumoto F, Kawagoe M, Matsui F. Urological emergency in neonates with congenital hydronephrosis. Int J Urol 2007;14:388-92.

7. Debnath J, Roy S, Sahoo SK, Pandit A. Congenital giant hydronephrosis: a rare cause for upper abdominal mass in the newborn. J Clin Neonatol 2013;2:33-5.

8. Atiyeh B, Husmann D, Baum M. Contralateral renal abnormalities in multicystic-dysplastic kidney disease.J Pediatr 1992;121:65-7.

9. Alconcher LF, Tombesi MM. Natural history of bilateral mild isolated antenatal hydronephrosis conservatively managed. Pediatr Nephrol 2012;27:1119-23.

10. Yang Y, Hou Y, Niu ZB, Wang CL. Long-term follow-up and management of prenatally detected, isolated hydronephrosis. J Pediatr Surg 2010;45:1701-6.

11. Liu DB, Armstrong WR 3rd, Maizels M. Hydronephrosis: prenatal and postnatal evaluation and management. Clin Perinatol 2014;41:661-78.

12. Şencan A, Şencan A. Antenatal hidronefrozun postnatal güncel yönetimi. Yeni Üroloji Dergisi 2014;9:73-8.

13. Güler M. Hekimler ve Tabip Odası Yöneticileri için Mevzuat. Kanun No:2827, Madde 5, birinci ve ikinci fikra, Türk Tabipler Birliği Merkez Konseyi. Ankara: 2001:107.

14. Rahman A, Katzive L, Henshaw SK. A global review of laws on induced abortion, 1985-1997. International Family Planning Perspectives 1998;24:56-64. 
15. Saul R. Abortion reporting in the United States: an examination of the Federal-State Partnership. Family Planning Perspectives 1998;30:244-7.

16. Gedikbaşı A, Gül A, Öztarhan K, Akın MA, Sargın A, Özek S, et al. Termination of pregnancy and reasons for delayed decisions. J Turkish-German Gynecol Assoc 2010;11:1-7.
17. Çorbacığlu A, Aslan H, Aydın S, Akbayır Ö, Ersan F, Alpay V, et al. Trends in fetal indications for termination of pregnancy between 2002 and 2010 at a tertiary referral centre. J Turkish-German Gynecol Assoc 2012;13:85-90

18. Akdeniz N, Kale A, Erdemoğlu M, Yalınkaya A, Yayla M. Etik kurul karariyla gebelikte tahliye edilen 126 olgunun geriye yönelik değerlendirilmesi. Perinatoloji Dergisi 2005;13:80-5. 